\title{
Sensoriamento remoto no monitoramento da qualidade dos recursos hídricos
}

Remote sensing in quality monitoring of water resources

\author{
1 Edson J. Silva \\ 1 Fernando Coelho fernando.eng.producao@hotmail.com \\ 2 Wesley Pinto da Silva
}

1 Fundação Centro Universitário Estadual da Zona Oeste, UEZO

2 Centro Universitário de Volta Redonda, UniFOA.

\section{Resumo}

A utilização do sensoriamento remoto para monitoramento da qualidade dos recursos hídricos tem crescido na última década, principalmente em virtude da redução de custos e da possibilidade de cobertura de uma área bem maior do que quando se utilizam métodos convencionais de coleta e análise qualitativa da água. A utilização do sensoriamento remoto permite uma estimativa confiável de dados ofertados, no entanto, essa tecnologia, embora amplamente utilizada para pesquisa, ainda carece de padronizações para leituras dos dados, além de uma melhor comunicação entre quem produz as imagens e quem as utiliza. Objetivou-se, com essa revisão, fazer uma análise dos principais métodos, ferramentas e parâmetros utilizados no monitoramento da qualidade dos recursos hídricos com uso do sensoriamento remoto.

\section{Palavras-chave}

Recursos hídricos; sensores; monitoramento; sensoriamento remoto.

\begin{abstract}
The use of remote sensing for monitoring the quality of water resources has grown over the past decade, mainly due to the cost reduction and the possibility of covering a much larger area than when conventional methods are used to collect and qualitative analysis of the water. The use of remote sensing allows a reliable estimate of offered data, however, this technology although widely used for research, still lacks standardization for data readings, as well as better communication between those who produce the images and those who use them. The objective of this review, do an analysis of the main methods, tools and parameters used in monitoring the quality of water resources using remote sensing.
\end{abstract}

\section{Keywords}

water resources; sensors; monitoring; remote sensing.

\section{Como você deve citar?}

SILVA, Edson J.; COELHO, Fernando; SILVA, Wesley Pinto da. Sensoriamento remoto no monitoramento da qualidade dos recursos hídricos. Cadernos UniFOA, Volta Redonda, n. 33, p. 121-130, abr. 2017. 


\section{INTRODUÇÃO}

A água constitui-se cada vez mais um bem escasso e limitado, devendo ser, portanto, um objeto de preocupação, já que constitui fonte essencial de vida. A redução de sua qualidade e disponibilidade é uma preocupação mundial e fundamental para a segurança alimentar e sustentabilidade ambiental (CICERELLI \& GALO, 2015).

O monitoramento da qualidade da água, através de métodos convencionais de coleta e análise, realizado pela Agência Nacional de Águas (ANA) no Brasil, além de elevado custo, mostra uma cobertura insuficiente, tendo em vista a grande extensão do país e um tempo médio de três a cinco meses para a disponibilização dos dados após a etapa de coleta. (GOMES \& BARBIERI, 2004)

Nesse contexto, a tecnologia de sensoriamento remoto surge como ferramenta alternativa para o monitoramento da qualidade dos recursos hídricos por apresentar menor custo financeiro e maior acessibilidade para realizar levantamentos técnicos, mapeamentos e monitoramentos para planejamento ambiental e urbano, como fonte de informação a ser integrada às convencionais, principalmente, com o advento dos satélites meteorológicos, a partir de 1960, e dos satélites de recursos naturais, a partir de 1970. Entretanto, apesar dessa tecnologia já ser utilizada amplamente em vários campos do conhecimento, seu uso pela comunidade gestora de recursos hídricos ainda é incipiente, em virtude de não haver um sistema de observação da Terra configurado com o objetivo único de dar suporte ao monitoramento das propriedades das águas doces. (NOVO, 2007a)

\section{SENSORIAMENTO REMOTO (SR)}

De acordo com Elachi (1987), pode-se definir sensoriamento remoto como a tecnologia que permite a aquisição de informações sobre objetos da superfície terrestre, a partir da detecção e mensuração das mudanças que eles impõem ao campo eletromagnético.

Segundo Vilela (2010), todo objeto que esteja a uma temperatura superior a $-273^{\circ} \mathrm{C}$ emite radiação eletromagnética. Essa radiação é emitida através de diferentes comprimentos de onda que variam ao longo do espectro, absorvida e espalhada na atmosfera, chegando à superfície e retornando aos sensores remotos. Os sensores são responsáveis pela conversão da energia proveniente da superfície em imagens ou gráficos, registrando informações espaciais (que permitem identificar forma e tamanho dos objetos, entre outras propriedades), informações sobre a intensidade da energia (que permitem quantificar a temperatura e o brilho) e informações espectrais (que permitem registrar a variação da intensidade da radiação que deixa a superfície ao longo do espectro eletromagnético), determinando, assim, as propriedades geofísicas e geométricas dos objetos da superfície.

Segundo Novo (2007b), todos os sensores apresentam três características básicas de resolução: (1) a resolução espectral, que expressa a largura das faixas de sensibilidade de cada banda do sensor; (2) a resolução espacial, que, de acordo com Rosa (2007), é a mínima distância entre dois objetos (alvos), na qual um sensor pode registrá-los como sendo objetos distintos e é medida em pixels; e (3) a resolução radiométrica, que é a maior ou menor capacidade de um sistema sensor em detectar e registrar diferenças de reflectância e/ou emitância dos elementos da paisagem, sendo a capacidade do sensor registrar o número de níveis de intensidade que compõem o pixel.

De acordo com Vilela (2010), a aquisição de imagens por sensoriamento remoto é uma forma rápida de obter informações sobre determinada região. 0 satélite americano Land-Sat tem grande utilização por possuir um grande acervo de imagens que são disponibilizadas gratuitamente. Ele foi 
desenvolvido pela NASA e é considerado um marco no desenvolvimento do sensoriamento remoto, pois foi o primeiro satélite lançado para observação da Terra, em 1972. 0 último satélite dessa série lançado foi o LandSat 8, em 2013. (NASA, 2013)

O LandSat 8 capta imagens de toda a superfície terrestre, seu período de revisita é de 16 dias (significa que o satélite leva 16 dias para passar pela mesma região) e os dados captados por seus instrumentos são disponibilizados gratuitamente na Internet. Os tamanhos de imagens gerados por esse satélite são de, aproximadamente, $170 \mathrm{~km}$ norte-sul por $183 \mathrm{~km}$ leste-oeste. (U.S. GEOLOGICAL SURVEY, 2013)

Os dados de sensoriamento remoto podem ser empregados no estudo de vários alvos espectrais, como solo, água, vegetação e rochas, pois cada alvo gera curvas espectrais diferentes, de acordo com sua reflectância, como mostrado na figura 1.

Analisando o gráfico, observa-se que a água limpa possui baixa reflectância, sendo maior na faixa visível $(0,45$ a $0,69 \mu \mathrm{m})$, principalmente a cor azul $(0,45$ a $0,52 \mu \mathrm{m})$ e sendo absorvida nas faixas do infravermelho $(0,76$ a $12,5 \mu \mathrm{m})$. Já o solo aumenta sua reflectância nas faixas do infravermelho e a vegetação é absorvida nas faixas do visível, passando a ser refletida nas faixas de infravermelho.

Figura 1 - Curvas de resposta espectral padrão da água, do solo e da vegetação.

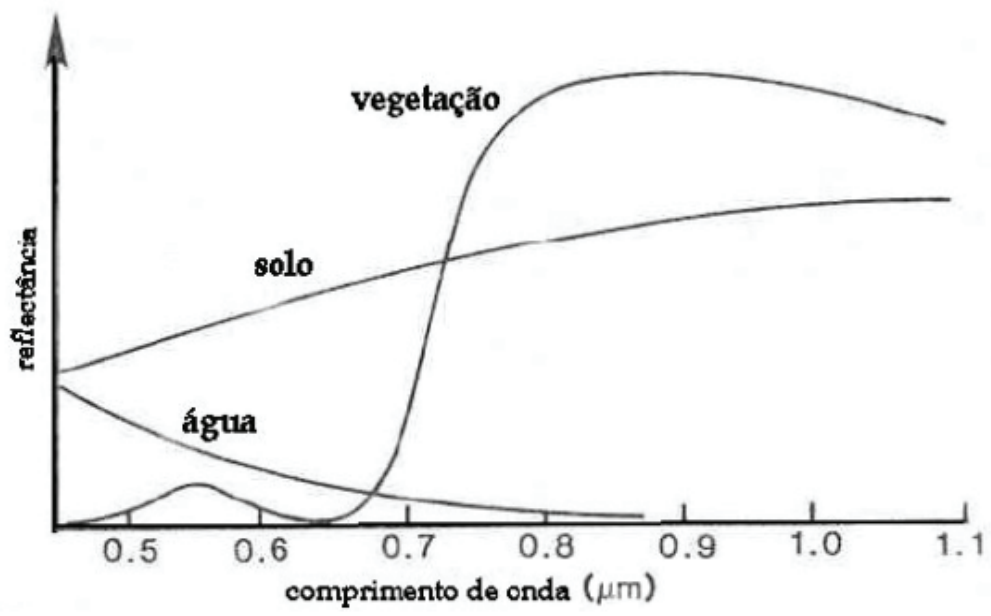

Fonte: Erbert. \& Haertel (2001)

\section{MONITORAMENTO DA QUALIDADE DOS RECURSOS HÍDRICOS POR SR}

0 território brasileiro apresenta mais de 8,5 milhões de $\mathrm{km}^{2}$, concentrando, em valores aproximados, $12 \%$ da água potável disponível no mundo. Ainda assim, o país enfrenta, em algumas regiões, graves problemas de abastecimento pelo crescente uso das terras próximas às bacias hidrográficas que acabam por reduzir a qualidade dos recursos hídricos locais por processos de eutrofização, caracterizado pela constante adição de matéria orgânica nas fontes hídricas (IBGE, 2013). Dessa forma, a determinação da qualidade da água, em termos práticos, não se restringe à determinação de sua pureza, mas às suas características importantes e desejadas para os seus diversos usos. Segundo Bilich et al. (2015), tanto as características físicas, químicas como as biológicas da água podem ser alteradas, na maioria dos casos, pela poluição, que pode ter diversas origens. 
Para o monitoramento da qualidade dos recursos hídricos é essencial obter dados dos corpos hídricos ao longo de sua extensão, entretanto, como citado acima, as grandes dimensões do território brasileiro inviabilizam a amostragem desse tipo por métodos tradicionais, sejam por custos operacionais ou simplesmente por demandarem um tempo expressivo, desde a amostragem até a análise e liberação dos dados. De acordo com Fraga et al. (2015), a amostragem de campo acaba por envolver uma grande quantidade de equipamentos e condições, uma vez que as imagens precisam ser trabalhadas em ambiente laboratorial, tornando o processo bastante oneroso e muitas vezes inviável.

De acordo com Hellweger et al. (2004), o uso de técnicas de sensoriamento remoto no monitoramento de recursos hídricos oferece três vantagens significativas sobre a amostragem em campo: (1) a cobertura contínua pelos imageadores a bordo de satélites permite uma estimativa sinóptica sobre grandes áreas; (2) a cobertura global dos satélites permite a estimativa da qualidade da água em locais remotos e inacessíveis; e (3) o vasto arquivo de imagens armazenadas permite e estimativa da qualidade da água ao longo do tempo. Por outro lado, também apresenta três desvantagens em relação ao método convencional: (1) dificuldade de distinguir constituintes da água, por exemplo, distinguir a assinatura espectral das macrófitas e do corpo d'água; (2) amostra de água limitada à superfície em ecossistemas oceânicos, variação com claridade da água e não controlável; e (3) resolução espacial e temporal pode ser inadequada e não controlável.

\section{PARÂMETROS ANALISADOS PARA GESTÃO E MONITORAMENTO DOS RECURSOS HÍDRICOS POR SR}

De acordo com Durand et al. (1999), quando se fala especificamente em sensoriamento remoto para a gestão de recursos hídricos, cinco parâmetros podem ser observados: os parâmetros físicos, químicos, biológicos, ecológicos e dinâmicos.

Os (1) parâmetros físicos estão relacionados à temperatura da água, condutividade, densidade, radioatividade, turbidez, cor e profundidade da zona eutrófica. Os (2) parâmetros químicos estão relacionados à salinidade, Fósforo total, Nitrogênio total, Carbono orgânico dissolvido, Carbono total, Sílica total, alcalinidade, pH, Oxigênio dissolvido, metais pesados, óleos e hidrocarbonetos clorados. Os (3) parâmetros biológicos estão relacionados a pigmentos clorofilados e acessórios, feopigmentos, demanda bioquímica de oxigênio, biomassa fitoplanctônica, contagem de fungos, biomassa zooplancton e concentração de detritos. Os (4) parâmetros ecológicos têm produção primária líquida, estado trófico da água, decomposição bacteriana, Grazin do fitopancton, biodiversidade fitoplanctônica, bacterioplancton, zooplancton, fungos e estado da biota. Finalmente, os (5) parâmetros dinâmicos se referem a sedimentos em suspensão, nível da água, tempo de residência, fluxo, estratificação de lagos e correntes e ondas (DURAND et al., 1999).

Mesmo com as todas as limitações já discriminadas, existem numerosos exemplos em que os dados obtidos por sensoriamento remoto podem ser usados para o monitoramento da qualidade e da quantidade de água. Silva et al. (2011), afirmam que o sensoriamento remoto pode ser usado como ferramenta para avaliar a dinâmica de vegetação em áreas extensas, com grau desejável de precisão. Miranda et al. (2015) utilizaram imagens de satélite para monitorar o crescimento de macrófitas aquáticas e entender as relações entre a dinâmica e o problemas ambientais. Andrade et al. (2015) afirmam o sensoriamento remoto tem sido aplicado com êxito em ambientes fluviais para monitorar a variação espacial e temporal da qualidade da água, verificando a origem, o deslocamento de substâncias especificas e compreender seus efeitos sobre os processos climáticos. 


\section{DETERMINAÇÃO DE VEGETAÇÃO AQUÁTICA}

As plantas aquáticas, conhecidas como macrófitas ou hidrófitas são vegetais que vivem em sistemas aquáticos continentais, com folhas imersas, flutuantes ou emersas e desempenham um papel extremamente importante no funcionamento dos ecossistemas em que ocorrem. São consideradas produtoras primárias das cadeias tróficas, atuam como habitat para outros organismos e se associam com bactérias fixadoras de nitrogênio. Além disso, atuam como bioindicadores do estado trófico dos ecossistemas aquáticos. Quando a reprodução intensa de macrófitas ocorre, podem indicar processos de eutrofização dos corpos hídricos, uma vez que os nutrientes atingem altas concentrações. As macrófitas, sejam emersas ou submersas, infestam o corpo d'água e podem alterar a qualidade da água (APARICIO \& BITENCOURT, 2015).

Pelo exposto, para a identificação de pontos de infestação dessa vegetação aquáticas, segundo Galo (2002), imagens orbitais multiespectrais podem ser usadas tanto para mapear a dispersão espacial e estimar a área de ocorrência de macrófitas aquáticas, como para orientar a definição de pontos de amostragem in loco, visando à coleta e posterior análise da água e de sedimentos nos reservatórios. Nesse sentido, o sensoriamento remoto permite a coleta de dados em grandes áreas, tais como lagos e rios extensos, pois permitem identificar de uma só vez os elementos vegetais presentes no espelho d'água. As imagens de satélite podem se constituir em um recurso auxiliar valioso no processo de alocar adequadamente pontos de amostragem no ambiente e mesmo de mapear a distribuição espacial de alguns componentes presentes no corpo d'água.

Considerando que, muitos desses bioindicadores se proliferarão em corpos d'água eutrofizados, com progressivo acréscimo de substâncias lançadas de esgoto residencial e comercial sem tratamento, das águas pluviais e de outros despejos urbanos além de outras substâncias agrícolas, justifica-se, então, o uso continuado de programas de monitoramento ambiental ao longo desse corpo hídrico, com uso do sensoriamento remoto (MARTINI et al., 2006).

\section{DETERMINAÇÃO DO PARÂMETRO CLOROFILA-A}

Outro parâmetro determinado pelo Sensoriamento Remoto no monitoramento da qualidade dos recursos hídricos é a clorofila-a e suas implicações à cor da água, propriedade que pode ser avaliada a partir de imagens de satélite.

Os modelos empíricos de estimativa de clorofila-a são aqueles que associam dados espectrais, provenientes de espectroradiômetros ou imagens de satélites, com medidas de concentração de clorofila-a por meio de modelos estatísticos. Eles são vastamente utilizados, principalmente, por sua praticidade. Historicamente essa metodologia foi desenvolvida para aplicações em águas oceânicas, que apresentam resultados convincentes, causados principalmente pela baixa variabilidade dos constituintes opticamente ativos, mas, especialmente na última década, os esforços têm se voltado para o estudo de águas de interiores. No entanto, essas águas (rios e lagos continentais) apresentam altas concentrações de clorofila-a, matéria orgânica dissolvida e de partículas orgânicas e inorgânicas em suspensão, que variam independentemente umas das outras. Essa variabilidade produz respostas espectrais de grande complexidade em que a matéria orgânica dissolvida e o material em suspensão interferem na resposta espectral dos pigmentos fotossintetizadores, tais como a clorofila-a, o que dificulta o ajuste de modelos estatísticos, como pode ser encontrada na literatura (CARVALHO et al. 2013).

Martini et al. (2006), citando Ansotegui et al. (2001), afirma que a clorofila-a é o pigmento mais importante na verificação da presença global de organismos fotossintetizantes na água e que os outros 
tipos de clorofilas e demais pigmentos são úteis como forma de identificar a presença ou dominância de certa classe de alga em uma amostra.

Dessa forma, os métodos empíricos de sensoriamento remoto são ferramentas úteis na determinação do nível trófico em programas de monitoramento ambiental ao longo de corpos hídricos e a partir de imagens de satélite é possível obter distribuição espacial da concentração de substâncias, tais como as de clorofila-a.

\section{UM BREVE HISTÓRICO DA LEGISLAÇÃO}

As primeiras experiências brasileiras, em termos de gestão e controle dos recursos hídricos no Brasil, tiveram inicio na década de 30 , necessariamente ligada à atividade agrícola. Nesse primeiro momento, foi criado o Código das Águas, estabelecido pelo Decreto 24.643/34 (BRASIL, 1934). Nas décadas seguintes, a legislação foi sendo aprimorada e, saindo de um modelo burocrático de gerenciamento de águas orientado por tipos de uso, teve início, em 1948, a segunda etapa da gestão dos recursos hídricos brasileiros, chamada de modelo econômico-financeiro, que se caracterizou pelo uso de instrumentos econômicos e financeiros, por parte do poder público, para a promoção do desenvolvimento nacional ou regional, além de induzir à obediência das normas legais vigentes. Essa etapa começou com a criação da Cia. de Desenvolvimento do Vale do São Francisco (Codesvasf), em 1948 (BRASIL, 1967).

As maiores discussões acerca da gestão e proteção dos recursos hídricos no Brasil iniciou-se a partir de década de 80 .

Nesse período, as águas interiores, as superficiais e as subterrâneas foram conceituadas como recurso ambiental pela legislação nacional, a partir da promulgação da Lei 6.938/81 (BRASIL, 1981), e pela Resolução Conama 001/86 (MMA, 1986).

Com a promulgação da Constituição de 1988, foram criadas as condições basais para instaurar a fase terceira da etapa da gestão de recursos hídricos, denominada modelo sistêmico de integração participativa (BRASIL, 1988).

Em 1997, foi sancionada a Lei 9.433, chamada Lei das Águas, a qual estabelece a Política Nacional de Recursos Hídricos, que incorpora princípios, normas e padrões de gestão de água universalmente aceitos e já praticados em diversos países (BRASIL, 1997).

\section{LEI 9.433 DE 1997 - LEI DAS ÁGUAS}

O sancionamento da Lei 9.433, em 08.01.97, inicia a Política Nacional de Recursos Hídricos. Essa lei significa uma nova raia institucional no país, pois congrega princípios, normas e padrões de gestão de água já aceitos e executados em diversas nações. A perspectiva governamental é de que ela atue tanto na manutenção dos recursos hídricos como ambientais de uma forma geral (BRASIL, 1997).

Inúmeras são as dificuldades e, atualmente, ainda é dificultoso a implementação do sistema de penalidades ou restrições para empresas de saneamento, indústrias ou propriedades rurais que despejam seus resíduos nos corpos hídricos. A lei preconiza que o uso da água tem que ser autorizado por instrumento da outorga, mediante cobrança, a fım de evitar desperdícios e uso indiscriminados. 
Dos princípios internacionalmente aceitos sobre gestão de recursos hídricos, incorporados à Lei 9.433, estão os fixados na Agenda 21, da Conferência Rio 92, que passaram por aperfeiçoamentos para serem factíveis e passíveis de serem implementados. São eles: a bacia hidrográfica é a unidade para a implementação da Política Nacional de Recursos Hídricos e para a atividade de gestão desses recursos; o gerenciamento dos recursos hídricos deve possibilitar sempre o múltiplo uso da água; a água é recurso natural limitado e que tem valor econômico; o gerenciamento dos recursos hídricos deve ser descentralizado e envolver a participação do governo, dos usuários e das comunidades locais; a água é propriedade pública; quando há escassez, a prioridade no uso da água é para o consumo humano e dos animais (ONU, 1992).

O reconhecimento do valor econômico da água é o alternador ao uso racional desse bem natural, servindo de base para a instituição da cobrança pela utilização dos recursos hídricos.

Outro fato importante é a gestão descentralizada. Os governos regionais e locais devem ter a responsabilidade pela tomada de decisão, retirando-se da União e das capitais estaduais essa prerrogativa. Além disso, a gestão participativa tem a prerrogativa de incluir os usuários e a sociedade organizada, em geral, no processo decisório.

Além dos princípios expostos, em acordo com as formulações da Agenda 21, a lei brasileira tem algumas orientações gerais para a administração dos recursos hídricos: a integração da gestão dos recursos hídricos com a gestão do meio ambiente; a coordenação do planejamento de recursos hídricos com os setores usuários e com o planejamento nos níveis nacional, estadual e municipal; a coordenação da gestão de recursos hídricos com o uso da terra; e a integração da gestão de bacias hidrográficas com a gestão dos sistemas costeiro e estuário.

Os instrumentos que a Lei 9.433 definiu como necessários à boa gestão do uso da água seguem a tendência da vanguarda mundial na administração dos recursos hídricos. São eles:

1. Plano Nacional de Recursos Hídricos - consolida todos os planos diretores de recursos hídricos de cada bacia hidrográfica, sendo sua elaboração de responsabilidade da Secretaria de Recursos Hídricos (SRH), do Ministério do Meio Ambiente.

2. Outorga do Direito de Uso dos Recursos Hídricos - instrumento pelo qual o usuário recebe uma autorização, concessão ou permissão, conforme o caso, para fazer uso da água.

3. Cobrança pelo uso da água - instrumento necessário para o equilíbrio entre a oferta e a demanda.

4. Enquadramento dos corpos hídricos em classes de uso - mecanismo necessário à manutenção de um sistema de vigilância sobre a qualidade da água. A classificação é feita com base em legislação ambiental.

5. Sistema Nacional de Informações sobre Recursos Hídricos - compreende a coleta, a organização, a crítica e a difusão da base de dados referente aos recursos hídricos, seus usos e o balanço hídrico de cada bacia, para prover os usuários e gestores com informações para o planejamento e a gestão. A centralização das informações desse sistema é realizada na SRH.

Em forma de estrutura de gerenciamento, estão previstos o Conselho Nacional de Recursos Hídricos (CNRH) e seus congêneres nos estados e no Distrito Federal, os Comitês de Bacias Hidrográficas 
e as Agências de Água. O CNRH é o órgão superior da hierarquia administrativa da gestão de águas, responsável pelas grandes questões do setor e pela resolução de contendas maiores.

Os Comitês de Bacias Hidrográficas apresentam-se na nova forma de organização no Brasil e contam com a participação de usuários, das prefeituras, de organizações civis e de representantes estaduais e federais. Os membros do comitê exercem o papel de um parlamento das águas da bacia, pois é o local de decisões sobre as questões relativas à bacia. As Agências de Água são o órgão técnico dos respectivos comitês, destinadas a gerir os recursos oriundos da cobrança pelo uso da água (BRASIL, 1997).

\section{CONCLUSÕES}

De acordo com os resultados desta revisão foi possível identificar que o uso do sensoriamento remoto, embora amplamente utilizado, apresenta grandes impasses no tocante à parametrização dos métodos, de forma que se se possa utilizar a ferramenta como fonte primordial para o monitoramento da qualidade dos recursos hídricos, no vasto território brasileiro.

Com os devidos ajustes nos métodos de identificação e interpretação dos dados, seria possível acessar pontos específicos de diversos corpos hídricos em qualquer local ou base estacionária, sem a necessidade da amostragem de campo para a confirmação dos dados fornecidos pelos sensores.

Salientamos a importância de um banco de dados espacial em nível nacional, facilitando o acesso e a disponibilidade de dados atuais e sinópticos a todos os órgãos do poder público e a toda a comunidade acadêmica e/ou pesquisadores das diversas instituições envolvidas com monitoramento ambiental.

O sensoriamento remoto e os sistemas de informações geográficas aliados aos modelos e estudos de utilização dos recursos hídricos possibilitam a obtenção mais rápida e precisa de dados.

\section{REFERÊNCIAS}

ANDRADE, L.R.M.; MELO, A.C.A.; NASCIMENTO, C.T.C ; AQUINO, F.G.; PACHECO, B.S. Correlação entre dados topográficos e de sensoriamento remote para caracterização de solos ultramáficos na região de Barro Alto, Goiás. Universidade de Brasília, Brasília, 2015.

ANSOTEGUI, A.; TRIGUEROS, J.M.; ORIVE, E. The use of pigments signatures to assess phytoplankton assemblage structure in estuarine waters. Estuarine, Coastal and Shelf Science, 52:689-703, 2001.

APARICIO, C; BITENCOURT, M. D. Resposta espectral de macrófitas aquáticas. IN: POMPÊO, M; MOSCHINICARLOS, V; SILVA, S. C; DOVAL, J. C. L. Ecologia de reservatórios e interfaces. São Paulo: Instituto de Biociências da Universidade de São Paulo, 2015. p. 177-189.

BRASIL. Constituição (1988). Constituição da República Federativa do Brasil: art. 20, inciso III, e art. 26, inciso I. Brasília, DF.

Decreto n²4643, de 10 de julho de 1934. Decreta o Código de Águas. Rio de Janeiro, RJ, 1934.

Decreto $n^{\circ} 292$, de 28 de fevereiro de 1967. Cria a Superintendência do Vale do São Francisco, Extingue a Comissão do Vale do São Francisco e dá Outras Providências. Brasília, DF, 1967. 
. Lei no 6938, de 31 de agosto de 1981. Dispõe Sobre a Política Nacional do Meio Ambiente, Seus Fins e Mecanismos de Formulação e Aplicação, e dá Outras Providências. Brasília, DF, 1981.

Lei nº 9433, de 08 de janeiro de 1997. Institui A Política Nacional de Recursos Hídricos, Cria O Sistema Nacional de Gerenciamento de Recursos Hídricos, Regulamenta 0 Inciso XIX do Art. 21 da Constituição Federal, e Altera 0 Art. $1^{\circ}$ da Lei $N^{\circ} 8.001$, de 13 de Março de 1990, Que Modificou A Lei № 7.990, de 28 de Dezembro de 1989.. Brasília, DF, 1997.

CARVALHO, L. A. S.; BARBOSA, C. C. F.; NOVO, E. M. L. M. Ajuste de bandas de modelos empíricos de estimativa de clorofila aplicados à região da planície de inundação do Lago Grande Curuai - PA. In: SIMPÓSIO BRASILEIRO DE SENSORIAMENTO REMOTO, 16. (SBSR)., 2013, Foz do Iguaçu. Anais... São José dos Campos: INPE, 2013. p. 8924-8931. DVD, Internet. ISBN 978-85-17-00066-9 (Internet), 97885-17-00065-2 (DVD). Disponível em: <http://urlib.net/3ERPFQRTRW34M/3E7GDML>. Acesso em: 20 out. 2015.

CICERELLI, Rejane E.; GALO, Maria de L. B. T.. Sensoriamento remoto multifonte aplicado na detecção do fitoplâncton em águas interiores. Rev. bras. eng. agríc. ambient., Campina Grande, v. 19, n. 3, p. 259-265, mar. 2015. Disponível em <http://www.scielo.br/scielo.php?script=sci_arttext\&pid=S1415$43662015000300259 \&$ Ing=pt\&nrm=iso >. Acesso em 15 out. 2015.

DURAND, D; SANDVEN, S.; POZDNYAKOV, D.;. CAUNEAU, F. ;WALD, L.. ; ,MILES, M.;KLOSTER, K.; JACOB, A. Characterisation of Coastal and Inland Waters with Space Sensors NERSC Technical Report No. 164 http://www.nrsc.no, 1999

ELACHI, C. . Introduction to the Physics and Techniques of Remote Sensing. XVII + 413pp. Chichester, New York, 1987.

ERBERT, M. ; HAERTEL, V. . Estudo das Técnicas de Classificação de Imagens Hiperespectrais Utilizando Análise Discriminante Regularizada - RDA. Porto Alegre: UFRGS, 2001 (Dissertação de Mestrado).

FRAGA, B. F.; IMAI, N. N.; ROTTA, L. H. S.; WATANABE, F. S. Y.; CARDOSO, M. F.; RODRIGUES, T. W. P.; ALCÂNTARA, E. H.; BARBOSA, C. C. F. Estimativa da concentração de sólidos suspensos e clorofila-a no Rio Bonito (SP): ajuste de modelos empíricos baseados na análise derivativa. In: SIMPÓSIO BRASILEIRO DE SENSORIAMENTO REMOTO, 17. (SBSR), 2015, João Pessoa. Anais... São José dos Campos: INPE, 2015. p. 1423-1430. Disponível em: <http://urlib.net/8JMKD3MGP6W34M/3JM4858>. Acesso em: 20 out. 2015.

GALO, M.L.B.T. et al . Uso do sensoriamento remoto orbital no monitoramento da dispersão de macrófitas nos reservatórios do complexo Tietê. Planta daninha, Viçosa, v. 20, n. spe, p. 7-20, 2002. Disponível em <http://www.scielo.br/scielo.php?script=sci_arttext\&pid=S0100-83582002000400002\&lng=pt\&nr $\mathrm{m}=$ iso>. Acesso em: 18 out. 2015.

GOMES, J. L.; BARBIERI, J. C.. Gerenciamento de recursos hídricos no Brasil e no Estado de São Paulo: um novo modelo de política pública. Cad. EBAPE.BR, Rio de Janeiro, v. 2, n. 3, p. 01-21, dez. 2004 . Disponível em <http://www.scielo.br/scielo.php?script=sci_arttext\&pid=S1679-39512004000300002\&ln $\mathrm{g}=$ pt\&nrm=iso>. Acesso em: 18 out. 2015.

HELLWEGER F. L.; SCHLOSSER, P.; LALLA, U. ; WEISSELC, J.K Use of satellite imagery for water quality studies in New York Harbor, Estuarine, Coastal and Shelf Science 61 437-44, 2004. 
IBGE. Instituto Brasileiro de Geografia e Estatísticas - IBGE. Área Territorial Oficial. Resolução $\mathbf{N}^{\circ} \mathbf{0 1}$, de 15 de janeiro de 2013. Disponível em: < http://www.ibge.gov.br/home/geociencias/areaterritorial/ resolucao_01_2013.shtm >. Acesso em: 28 out. 15.

MARTINI, L. C. P. et al . Uso de sensoriamento remoto orbital para avaliação da distribuição espacial de Clorofila_a na Lagoa da Conceição - Florianópolis, SC. Eng. Sanit. Ambient., Rio de Janeiro, v. 11, n. 4, p. 318-324, dez. 2006. Disponível em <http://www.scielo.br/scielo.php?script=sci_arttext\&pid=S141341522006000400004\&lng=pt\&nrm=iso>. Acesso em: 18 out. 2015.

MIRANDA, J. C. S.; COSTA, S. M. F. Estudo de macrófitas aquáticas utilizando imagens orbitais em um trecho do rio Paraíba do Sul. In: SIMPÓSIO BRASILEIRO DE SENSORIAMENTO REMOTO, 17. (SBSR), 2015, João Pessoa. Anais... São José dos Campos: INPE, 2015. p. 3972-3979. Internet. ISBN 978-8517-0076-8. Disponível em: <http://urlib.net/8JMKD3MGP6W34M/3JM4CA8>. Acesso em: 19 out. 2015.

MMA. Ministério do Meio Ambiente. Res. Conama No 001 de 23 de janeiro de 1986. Considerando a necessidade de se estabelecerem as definições, as responsabilidades, os critérios básicos e as diretrizes gerais para uso e implementação da Avaliação de Impacto Ambiental como um dos instrumentos da Política Nacional do Meio Ambiente. Brasília, DF, 1986.

NASA. National Aeronautics and Space Administration., Landsat History, 2013. Disponível em <https:// www.nasa.gov/mission_pages/landsat/main/index.html> . Acesso em: 02 jun. 2016.

NOVO, E.M.L.M. Monitoramento de Quantidade e Qualidade da Água e Sensoriamento Remoto, XVII Simpósio Brasileiro de Recursos Hídricos, São Paulo, 2007a

Sensoriamento Remoto: Princípios e Aplicações. São Paulo, Ed. Blucher, 269 p. $3^{\circ}$ ed. (in press). $2007 \mathrm{~b}$

ONU. Conferência das Nações Unidas para o Meio Ambiente e o Desenvolvimento. Agenda 21, Capítulo 18. Protection of the quality and supply of freshwater resources: Application of integrated approaches to the development, managment and use of water resources, 1992.

ROSA, R. .Introdução ao Sensoriamento Remoto. 6. ed. Uberlândia: EDUFU, 2007.

SILVA, T.S.F., COSTA, M.P. MELACK, J., NOVO, E.M.M. Influência de variações na intensidade do pulso de inundação sobre a cobertura e crescimento da vegetação herbácea aquática na Amazônia. SIMPÓSIO BRASILEIRO DE SENSORIAMENTO REMOTO, 1., São José dos Campos. Anais. São José dos Campos: INPE. p.3205-3212, 2011.

U.S. GEOLOGICAL SURVEY, LandSat 8, 2013. Disponível em: <http://landsat.usgs.gov/> Acesso em: 02 jun 2016.

VILELA, M.A.M.A. Metodologia para Monitoramento da Qualidade da Água de Reservatórios utilizando Sensoriamento Remoto. Dissertação de Mestrado. Universidade Federal de Uberlândia, 2010. 